\title{
Cognitive reserve, cortical plasticity and resistance to Alzheimer's disease
}

\author{
Margaret M Esiri*1,2 and Steven A Chance'
}

\begin{abstract}
There are aspects of the ageing brain and cognition that remain poorly understood despite intensive efforts to understand how they are related. Cognitive reserve is the concept that has been developed to explain how it is that some elderly people with extensive neuropathology associated with dementia show little in the way of cognitive decline. Cognitive reserve is intimately related to cortical plasticity but this also, as it relates to ageing, remains poorly understood at the present time. Despite the shortcomings in understanding, we do have some knowledge on which to base efforts to minimise the likelihood of an elderly person developing dementia. For some risks the evidence is far from secure, but resistance to Alzheimer's disease (AD) appears from epidemiological studies to be contributed to by avoiding hypertension in middle life, obesity, depression, smoking and diabetes and head injury and by undertaking extended years of education, physical exercise, and social and intellectual pursuits in middle and late life. Nutritional factors may also promote healthy brain ageing. Resistance to $A D$ is also contributed to by genetic factors, particularly apolipoprotein E2, but some combinations of other genetic polymorphisms as well. Although multiple factors and possible interventions may influence cognitive reserve and susceptibility to dementia, much more work is required on the mechanisms of action in order to determine which, if any, may improve the clinical and epidemiological picture. Understanding of how such factors operate may lead to new initiatives to keep the elderly population in the 21 st century able to lead active and fulfilling lives.
\end{abstract}

*Correspondence: Margaret.esiri@clneuro.ox.ac.uk

2Department of Neuropathology, Oxford Radcliffe NHS Trust, Oxford OX3 9DU, UK Full list of author information is available at the end of the article

\section{Introduction}

The early 21 st century confronts us with a dual dilemma concerning old age: first, there is going to be an enormous increase in the number of elderly people, and second, there is at present very little that can be offered to help those many people who become demented. The best way to confront these twin difficulties must be to maximise the chances of elderly people avoiding cognitive decline and dementia. But how is this to be done?

We know that advancing age is by far the largest risk factor for developing sporadic dementia but we also know that there is a wide range of cognitive performance in old age. What attributes determine the cognitive fate of individual elderly people? Here we review what is known about this important subject.

\section{The concept of cognitive reserve}

The brain undergoes changes in structure, metabolism and function as it ages [1,2]. While some of these changes are apparent on examining the brain of an elderly person, whether by imaging when they are alive or by postmortem examination, others are not. Some of the changes are well established as relating to cognitive decline and dementia, most notably the pathological features of Alzheimer's disease (AD), but also cerebrovascular disease and alpha synuclein pathology. Yet it has become clear from unselected epidemiological studies linked to neuropathology that there is not infrequently a mismatch between pathological changes found post-mortem and the recorded cognitive performance of a person before they died [3]. In some cases cognitive performance is below the level expected for the amount of pathology found but more frequently someone with a substantial load of pathology had nonetheless performed cognitively within the normal range before death. A recent large study found that careful quantification of neuropathology and brain weight accounted for only between a third and a half of the variance in cognitive performance in a relatively unselected group of elderly people, leaving the rest unaccounted for [4]. Cognitive reserve is the concept that has been developed to deal with this discrepancy [5].

Potential issues of measurement error arise when considering the concept of cerebral reserve relating to 
ceiling and floor effects in testing instruments but, in general terms, most investigators attribute at least some cognitive reserve to having a well developed and nourished brain with an abundance of synapses and healthy neurons in those parts of the brain that are concerned with cognition - mainly association cortex, hippocampus and the parts of the brain that these are connected to. This hypothesised basis for cognitive reserve fits quite well with the fact that longer years of education protect against dementia and, conversely, with the enhanced risk of dementia experienced by those who have had a serious head injury. This concept particularly links cognitive reserve to grey matter regions of the brain and to the cortical plasticity inherent in these. However, there are also changes in the white matter of the brain that are increasingly recognised with ageing, and some of these are not readily explained as secondary to the grey matter changes. Thus, we need to consider the evidence for both grey and white matter contributions to cognitive reserve.

\section{Grey matter, cortical plasticity and cognitive reserve}

Not all forms of reserve are the same, and they depend on the forms of brain insult and neuroplasticity that may be involved. Stern [6] has compared neural compensation, neural reserve, and cognitive reserve. Neural compensation and neural reserve are characterised as 'taskdependent' in contrast to more generalised cognitive reserve. Compensation is a response to pathologically altered processing, whereas reserve refers to differences in task-related processing without pathology. Stern considers all three to be 'neural mechanisms' in the sense that they are attributed to interactions within neural networks. However, the relationship between cognitive reserve and its architectural neural basis is not clear. Part of the explanation for the large proportion of variance that remains unexplained in the study by Dowling and colleagues [4] is that neuropathological measures are unlikely to account fully for cognitive ability. Reed and colleagues [7] have used the mis-match between pathology and cognitive performance as an index of neural reserve. This measure merges the neuropsychological domain and the neuropathological domain. However, such a measure depends on the presence of pathology and therefore does not offer insight into the potential reserve that exists prior to the onset of pathology. As an alternative, an appropriate measurement of intact architecture should provide a neuroanatomical index that precedes pathology, changes with normal ageing, and correlates with cognitive ability [8].

In previous work [9] we have drawn attention to a distinction in the neuroanatomical domain - between the markers of neuropathological processes, such as plaques and tangles, and measurement of the remaining, intact cerebral architecture that is presumably the basis for ongoing cognitive function. It is notable that most assessments of cognitive deficit are in fact measures of remaining function (that is, reduced measures of positive ability). Therefore, assessing the degeneration of intact structure is as important as the accumulation of pathology. Synapse loss [10] and minicolumn change [9] have shown some of the clearest structural relationships with functional deficits in ageing and dementia. In the context of identifying a neural basis for cognitive reserve, pathological markers may be identified with deficit, whereas measures of intact architecture should correspond to reserve.

\section{Structural changes}

At the large scale, total brain size contributes significantly to the variance in cognitive ability between individuals [4]. Total brain shrinkage typically occurs with ageing in humans, which a recent report suggests may be unusual compared to other primates who do not show this reduction [11]. In a longitudinal MRI study of twins in adulthood, progressive thinning of the frontal cortex and thickening of the medial temporal cortex is heritable and related to cognitive ability (IQ) [12]. (IQ measures are taken to be a good indicator of premorbid cognitive reserve [13].) Genes influencing variability in both intelligence and brain plasticity partly drive these regional associations. In particular, training in alternative problem solving strategies likely to be associated with prefrontal cortex (PFC) function has been linked to enhancement of cognitive reserve. Our own data have found a closer relationship between cognitive function and microanatomical measures in association cortex than with total brain size [9] (see below).

Older adults are capable of counteracting age-related neural decline through plastic reorganization of neurocognitive networks. At the small scale, on the structural level, several aspects of neuroplasticity occur in adult brains, including alterations of dendritic arborisation, synaptic remodelling, axonal sprouting, neurite extension, synaptogenesis, and neurogenesis [14]. The hippocampus is a region of high neuroplasticity, with ongoing myelination and neurogenesis during adulthood $[15,16]$. The PFC is also a dynamic structure, capable of a neuroplastic response to changes or damage with an extended period of development during childhood and adolescence, and a decline in adulthood in humans [17].

The neuroplasticity hypothesis therefore offers a mechanism to help explain differential regional vulnerability in $\mathrm{AD}[18,19]$. It suggests that differences in disease progression are due to different intrinsic rates of neuropathological change, related to regional differences in neuroplasticity. Ageing makes neurons work harder to meet neuroplastic demands. A model incorporating 
intrinsic vulnerability (for example, [14]) therefore offers a link to normal aging. Grafman and Litvan [20] have identified four major forms of neuroplasticity: map expansion (mainly due to skill learning), cross-modal reassignment (by rewiring following injury), homologous area adaptation (the shift of function, often to the opposite hemisphere, due to injury in early life), and compensatory masquerade (an alternative processing strategy for a task). These forms of neuroplasticity tend to be responses to specific events or tasks. However, there is also evidence of an over-arching trajectory of change in structure across the lifespan [21], to which the contribution of these event-driven forms of plasticity is uncertain. Rosenzweig [22] has reviewed the range of mechanisms of neuroplasticity across the lifespan, and Gopnik [23] describes a contrast in learning strategies and plasticity in childhood compared to adulthood. It is the latter stage of persistent adult neuroplasticity that is likely to be most relevant for determining the effects of age and dementia on cognitive reserve (although see 'Stem cells and neurogenesis' section below).

Age-related dendritic growth reflects hierarchical organisation between cortical regions [24], with greater growth in limbic and association cortex where there is greater arborisation contrasted with stability or regression in less complex primary cortex [25]. Regional differences in the width of minicolumns (the radial columns of cells that constitute the cerebral cortex) also reflect this hierarchy [19]. The minicolumns become thinner with age [24] and we have shown that the relationship between minicolumns and cognitive function in association cortex is independent of general brain atrophy [8]. Furthermore, in $\mathrm{AD}$, a higher density of tangles occurs in the more plastic regions and is correlated with the degree of minicolumn disruption [26].

Not all regions associated with extended plasticity in adulthood are early casualties in AD; for example, dorsolateral PFC is affected later. The expression of plasticity as a risk factor may be compensated by the availability of neural reserve. A study of the dorsolateral PFC found that the microstructure changed with normal ageing and that minicolumn thinning and accumulating plaque load mirrored the decline in IQ [8]. The role of the PFC in cognitive reserve indicates that the thinning of minicolumns in the PFC may reflect the loss of the initial neural reserve (for example, loss of neuropil and neuronal connections) in early aging. We also found that $\mathrm{AD}$ patients with a high IQ were older at time of death compared to patients with a low IQ score and the density of tangles was less in the patients with high IQ. The implication is that individuals with greater reserve tend to develop dementia later in life. Moreover, the low density of tangles with high IQ raises the possibility that, in addition to neural reserve and neural compensation, cognitive reserve may be associated with 'neural resistance' to the spread of pathology.

One possibility is that different regional connectivity contributes to different plastic demands and different aspects of cognitive reserve. For example, the serial connections of the entorhinal-hippocampal pathway are more constrained than the diverse connections of the polymodal prefrontal cortex, reducing the options for neural compensation. One consequence may be the requirement for sustained adult neurogenesis in the hippocampal region while the preservation of white matter connectivity may be relatively more important in the PFC.

\section{White matter and cognitive reserve}

White matter atrophy was highlighted in 1989 when, in a quantitative neuropathological study of elderly brains, it was found that people without cognitive decline but with some AD pathology had atrophy of white matter but not of grey matter, whereas those with dementia and more extensive AD pathology had both grey and white matter atrophy. It was suggested that white matter atrophy may precede whole brain atrophy in ageing brains [27].

Neuroimaging has taken this concept further. O'Sullivan and colleagues [28] described reduced diffusional anisotropy, a measure of white matter integrity, and higher mean diffusivity in elderly people with normal cognitive performance for age compared with young control subjects. Another early diffusion tensor imaging study identified reduced white matter integrity in the splenium of the corpus callosum, superior longitudinal fasciculus, and cingulum whereas the pyramidal tracts were spared [29]. Bartzokis and colleagues [30] found, using the transverse relaxation rate, that people who were ApoE4-positive, and therefore at increased risk to develop AD (though they performed cognitively normally when examined), had a reduced cognitive processing speed, which was significantly correlated with myelin breakdown in late myelinating white matter regions. Presymptomatic carriers of familial AD mutations have altered diffusion tensor imaging signal in white matter throughout the brain and particularly in the perforant pathways, the fornix, and orbito-frontal white matter [31]. It was suggested that the changes in the fornix in particular may provide a biomarker for early disease in sporadic AD.

Andrews-Hanna and colleagues [32] used functional MRI signal correlations between regions within largescale brain systems in young and old cognitively normal subjects (mean Mini-Mental State Examination in the elderly score of 28.8) and showed marked reductions with age in normally present functional correlations within two higher order brain systems. The worst affected system was the anterior to posterior components within 
the default network. Reduced correlations were associated with loss of white matter integrity.

Abnormalities in the default mode network were also detected using resting state paradigms in mild cognitively impaired subjects [33]. The level of deactivation differed in the anterior frontal, precuneus and posterior cingulate in $\mathrm{AD}$ when compared to controls, and the level of deactivation was intermediate in mild cognitive impairment. Both studies suggest activity in the default mode network may provide a marker for early changes and indicate continuity between normal ageing and so-called pathological ageing.

The pathological basis of this purported white matter deterioration with ageing, which occurs in the absence of overt white matter changes such as hyperintensity on T2 imaging, is not well delineated, but Bartzokis [34] has suggested that dysfunction of oligodendrocytes and the myelin sheaths they maintain may be to blame.

\section{Resistance to Alzheimer's disease}

This review has so far considered mainly changes that occur in the brain with normal ageing. Although there are some investigators who prefer to consider $\mathrm{AD}$ as distinct from ageing, we believe that there may be more advantages in regarding it as part of the spectrum of change that occurs in the brain with age. This approach is borne out by the enhanced associations that have been found of pathology with AD genetic susceptibility alleles if analyses involve not only neuropathological cases of definite AD but also other elderly cases with less marked AD pathology, referred to in the study by Bennett and colleagues [35] as 'intermediate phenotypes'. This was also the approach to linking neuropathological variables and a range of cognitive scores in elderly subjects that was taken by Dowling and colleagues [4]. There are so many changes that are seen to a severe degree in definite $\mathrm{AD}$ and to a milder degree in normal ageing that this 'intermediate phenotype' model seems to make eminent sense. These include evidence in the brain of oxidative and other free radical damage, reduced anti-oxidative capacity, loss of synapses, expression of cell division cycle markers and neurons displaying hyperploidy, to name but a few. It is acknowledged that there may be step-wise blips within a spectrum of age-related changes encompassing $\mathrm{AD}$ that may influence cognitive performance and be marked by particular pathological changes, as suggested by Herrup [36]. Nevertheless, in the rest of this review, in which we consider what may constitute 'resistance' to $\mathrm{AD}$, we shall follow this 'intermediate phenotype' approach and include 'resistance to brain ageing'.

Factors that may protect an individual from progressing to the $\mathrm{AD}$ end of the spectrum of possible change as they age are legion. A recent review considered seven modifiable risk factors for $\mathrm{AD}$ and calculated that up to half of cases of AD might be attributable to such factors: diabetes, midlife hypertension, midlife obesity, smoking, depression, cognitive inactivity or low educational attainment and physical activity [37]. These factors are derived mainly from epidemiological studies and not from interventional studies, which at present remain inadequate [38]. These can be classified according to whether they are thought to act by strengthening brain reserve before it is assaulted by the effects of age on the one hand and those that constitute a reaction to such assaults on the other. It is beyond the scope of this review to examine these factors in detail but we shall give them brief consideration here.

\section{Psychosocial factors}

The important factors here are avoidance of depression, itself seemingly partly dependent on healthy maternal influences on the fetus, or, more realistically, prompt recognition and treatment of depression; extended years and quality of education, captured by tests of reading ability; and abundant leisure, exercise and cognitive activities in middle and early old age [7,37,39]. A broad category of cognitive enrichment includes physical, mental, and social activities that may improve adult cognitive function [40]. Clare and colleagues [41] have identified three categories of intervention: 'cognitive stimulation' involves non-targeted procedures to enhance general mental function, 'cognitive training' involves theory-driven intervention, and 'cognitive rehabilitation' tackles impairments resulting from neuropsychiatric disorders. In normal ageing, engagement in daily arithmetic puzzles has been shown to improve function in a randomized controlled trial [42]. How behavioural and psychosocial enrichment strategies might interact with psychopharmacological enhancement in healthy subjects is unclear, but it seems reasonable to hypothesise that it strengthens cognitive reserve. Rozzini and colleagues [43] found enduring improvement in mild cognitive impairment patients receiving combined pharmacological therapy and cognitive training in a one-year randomized study (although subjects receiving only pharmacological intervention also improved). However, it has been suggested that cognitive training is of limited benefit in demented subjects [41].

\section{Vascular risk factors}

Vascular risk factors seem, from epidemiological studies, to operate particularly at the middle stages of life. Hypertension, in particular, needs to be avoided and other risk factors for $\mathrm{AD}$ that probably act through an effect on vascular risk also need to be avoided: smoking, obesity and diabetes. Diet, which also feeds into the risks of obesity and vascular disease, may also be protective if it avoids much saturated fat and is rich in sources of 
vitamins, omega-3 fatty acids and anti-oxidants (for example, curcumin). There is some evidence that vitamins B12, folate and B6 are protective (by reducing blood homocysteine levels) [44], as is resveratrol in red wine. While epidemiological evidence for these protective factors is quite strong, evidence that adopting them is effective in preventing $\mathrm{AD}$ is less sound or even negative, probably because they have been applied in trials too late in the course of the disease and for too short a period of time. These factors likely operate by preventing brain pathology.

There are several putative mechanisms through which such dietary factors may act. Taking omega- 3 fatty acids as an example, docosahexaenoic acid (DHA) is the main omega-3 fatty acid in the brain and an essential component of synaptic membrane phospholipids, and consequently may play a role in synaptic remodelling [45]. DHA attenuates amyloid- $\beta$ secretion, an effect accompanied by neuroprotectin D1 formation, which promotes brain cell survival [46]; DHA also protects from dendritic pathology in an AD mouse model [47]. Furthermore, another omega-3 fatty acid, eicosahexaenoic acid, is an anti-inflammatory precursor. Consequently, omega-3 fatty acids are involved in gene expression differences, synaptic plasticity and dendritic structural changes that plausibly contribute to cognitive reserve.

Evidence for an effect of hormones on AD risk is controversial but increasing. Thus, testosterone acts as a protective factor in men [48] and oestrogen replacement therapy may be protective if administered initially at or shortly after the menopause (but not later) in women [49]. Raised cortisol levels are thought to represent a risk factor for $\mathrm{AD}$ and therefore need to be avoided by limiting stress. Raised cortisol levels may explain, at least in part, the manner in which depression promotes AD.

There is good evidence that physical activity both in old age and earlier in life protects against AD. It may do this in part by protecting against vascular risk factors such as hypertension, obesity and diabetes, but it also appears to protect the brain more directly by promoting growth factor production and neurogenesis (see below).

Much has been written about the importance of systemic and brain inflammation in influencing AD risk. The pathology of AD includes enhanced activation of microglial cells, and the remarkable ability of macrophages to eliminate beta amyloid from the brain in experimental AD drew attention to the power of these cells to influence pathological events in this disease [50]. There is some epidemiological evidence that chronic inflammatory diseases such as rheumatoid arthritis and leprosy, requiring long-term treatment with anti-inflammatory agents, are protective against $\mathrm{AD}$ [51] but attempts to treat $\mathrm{AD}$ or mild cognitive impairment with anti-inflammatory therapy have had disappointing results. Avoidance of head injury may be protective against AD at least in part because head injury is a cause of brain inflammation, although there may be a more direct link between head injury and amyloid plaque formation [52]. Inflammation may be influenced by systemic and local infections. For example, latent herpes simplex infection of the brain is one of several infections that have been suggested to influence risk of AD [53].

\section{Cellular mechanisms in the brain}

Cortical and hippocampal neurons are critical elements that need protection in old age and as a part of the resistance to AD. Neurons' dependency on oxidative metabolism is a source of danger as mitochondria become less efficient with age as a consequence of their generation of free radicals, which then damage the mitochondria themselves as well as other cellular constituents. The enormous cell surface area that requires constant maintenance is also an Achilles' heel for many neurons as it increases the need for energy, which, in turn, is dependent on mitochrondrial function. A third source of difficulty in maintaining healthy neurons in old age is their vulnerability to excitotoxic damage mediated through excess stimulation of glutamate receptors. To defend themselves against free radical damage, cells require effective antioxidant mechanisms, with which neurons are not overly endowed. Some of the dietary and lifestyle habits that protect against $\mathrm{AD}$ probably operate through boosting anti-oxidant mechanisms either directly or indirectly.

Glial cells also play important protective roles. Astrocytes are known for their neuroprotective properties, such as release of growth factors, control of potentially neurotoxic transmitters and promotion of neuroprotective effects of oestrogens [54,55], although they have recently been shown in co-cultures of neurons and astrocytes to be critically involved in the toxicity that betaamyloid has for neurons [56]. Microglia may have altered properties in the ageing brain that enhance their ability to exert neurotoxic effects $[57,58]$.

As reviewed by Iadecola [59], brain endothelial cells have critical roles to play in the fine tuning of oxygen and metabolite supply from the blood to the brain in response to neural activity and in enabling waste products of such activity to be removed. They also exert a protective effect on nerve cells by producing growth factors such as brainderived neurotrophic factor. These endothelial cells are subjected to oxidative damage and toxic effects of betaamyloid produced in the brain, which can compromise these functions during ageing and promote endothelial cell autophagy. In transgenic AD in mice there are changes in cerebral blood flow regulation long before there is evidence of beta-amyloid deposition in the brain, suggesting that vascular changes occur at a very early stage in the pathogenesis of genetically determined AD. 
Table 1. Some protective genetic effects against Alzheimer's disease

\begin{tabular}{|c|c|c|c|c|}
\hline Gene(s) & SNP(s) & $\begin{array}{l}\text { Control allelic } \\
\text { frequency }\end{array}$ & $\begin{array}{l}\text { Control combination } \\
\text { frequency }\end{array}$ & $\begin{array}{l}\text { Odds ratio of } \\
\mathrm{AD}(95 \% \mathrm{Cl})\end{array}$ \\
\hline \multicolumn{5}{|c|}{ Effects attributable to single genetic loci } \\
\hline CLU & rs1113600AvsG & A: $40 \%$ & & $0.88(0.86-0.90)^{\mathrm{a}}$ \\
\hline PICALM & rs3851179AvsG & A:36\% & & $0.88(0.86-0.90)^{\mathrm{a}}$ \\
\hline CD33 & rs3865444VvsC & A:32\% & & $0.89(0.86-0.92)^{\mathrm{a}}$ \\
\hline \multicolumn{5}{|c|}{ Effects attributable to two-locus combinations } \\
\hline \multirow[t]{2}{*}{$A P O E$} & rs429358/rs7412 & & $9.1 \%$ & $0.44(0.39-0.50)^{b}$ \\
\hline & $\varepsilon 2$ vs others & & & \\
\hline \multirow[t]{2}{*}{ PPARA, IL1A } & rs4253766/rs378550 & & $11.4 \%$ & $0.71(0.57-0.90)^{\mathrm{b}, \mathrm{c}}$ \\
\hline & $(\mathrm{TC}+\mathrm{TT}) /(\mathrm{CA}+\mathrm{CC})$ vs others & & & \\
\hline \multirow[t]{2}{*}{ PPARA, ILIB } & rs1800206/rs16944 & & $11.6 \%$ & $0.74(0.60-0.92)^{b, c}$ \\
\hline & $(\mathrm{GC}+\mathrm{GG}) /(\mathrm{GA}+\mathrm{GG})$ vs others & & & \\
\hline
\end{tabular}

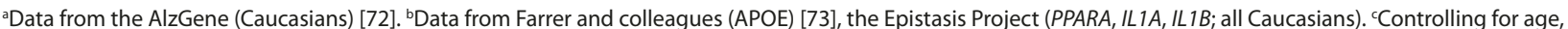
sex and APOE4. AD, Alzheimer's disease; $A P O E$, apolipoprotein $\mathrm{E} ; C D 33, C D 33$ antigen; $C l$, confidence interval; $C L U$, clusterin; IL $1 A$, interleukin-1a; IL1B, interleukin-1 3 PICALM, phosphatidyl inositol-binding clathrin assembly protein; PPARA, peroxisome proliferator-activated receptor-a. Data in Table 1 are courtesy of DJ Lehmann.

\section{Stem cells and neurogenesis}

In animal experiments, both voluntary exercise and environmental enrichment stimulate adult hippocampal neurogenesis. Running can in part reverse the decrease in neurogenesis observed in aged animals and improves learning in aged animals [60]. Sequentially combining the effects of physical activity with environmental enrichment has been shown to have an additive effect on the number of new neurons in the dentate gyrus [61]. Kempermann and colleagues [62] have proposed that continued physical and mental activity maintains a 'neurogenic reserve' of potential neurons that may be integrated into the hippocampal network. However, the number of precursor cells that may be recruited is limited by the proliferative cells, whose survival may depend on activity in early life. This links later life reserve to activity in early life and indicates that early life behaviour can only be partly compensated later. The interaction is reminiscent of Hebb's original finding that early experience influences problem-solving ability in maturity [63].

New cells in the hippocampus initially express increased synaptic plasticity and it has been claimed that all longterm potentiation in the dentate gyrus originates from new cells; meanwhile, long-term potentiation has been shown to induce adult hippocampal neurogenesis in vivo [62]. Of additional interest, considering that therapeutic neuropharmacology for AD has predominantly targeted the cholinergic neurotransmitter system, cholinergic input from the medial septal area promotes precursor cell proliferation in the dentate gyrus [64]. Environmental enrichment also leads to increased cortical acetylcholinesterase activity [65], although the clinical manipulation of acetylcholine levels in dementia has met with limited success.
The potential role of neurogenesis in cognitive reserve and its manipulation in old age has received considerable attention [66], although much is yet unknown regarding possible intervention in humans. The indication of neurogenesis in association cortex but not in a primary sensory area (striate cortex) in monkeys [67] hints at more widespread neurogenesis reflecting some of the brain region hierarchical differences already mentioned. However, the generality of ongoing neurogenesis in 'higher' neocortical regions is uncertain (for example, [68]), especially in humans.

\section{Genes}

Genes are thought to have a major impact on AD risk and probably many of the psychosocial and lifestyle factors mentioned above exert their effects by altering the epigenetic control of gene expression [69]. Although the gene encoding apolipoprotein $\mathrm{E}$ is most well established as influencing risk of late onset $\mathrm{AD}$, several other gene polymorphisms have also emerged from recent studies as having a modest effect on AD risk (Table 1). Combinations of gene polymorphisms appear to have a stronger influence than single gene effects.

SIRT1 is a gene that profoundly influences life span in rodents and is activated by calorie restriction, an intervention that has long been recognised as extending the lifespan of rodents by $50 \%$ or more. SIRT 1 codes for an acetylase that counteracts the effects of stress on cells. Overexpression of SIRT1 in AD transgenic mice reduced beta-amyloid production, inflammation, tau phosphorylation and improved learning [70]. A substance in red wine, resveratrol, has SIRT1-activating effects. Another signalling pathway that influences life span and experimental expression of AD transgenes is the target of 
rapamycin (mTOR) pathway. Long-term inhibition of this pathway by the drug rapamycin delayed the expression of cognitive decline and pathology in AD transgenic mice [71]. The SIRT1 and mTOR pathways are promising with regard to the development of interventions to prevent or slow the development of AD in humans.

\section{Conclusion}

We already have some knowledge on which to base preventive strategies to keep $\mathrm{AD}$ at bay. These strategies are already recognised to promote healthy ageing of the vascular system, and they are likely to be joined within a few years by additional novel measures based on rapidly developing understanding of the effects of ageing on the brain. But there are formidable challenges to be overcome, as witnessed by the widespread surge in obesity that could threaten to undermine attempts to improve the chances of many people enjoying a prolonged and fulfilled old age.

\section{Abbreviations}

AD, Alzheimer's disease; DHA, docosahexaenoic acid; MRI, magnetic resonance imaging; PFC, prefrontal cortex.

\section{Competing interests}

The authors declare that they have no competing interests.

\section{Acknowledgements}

We are grateful to DJ Lehmann (Oxford Project to Investigate Memory and Ageing (OPTIMA), Pharmacology Department, University of Oxford) for provision of the data in Table 1. MME has financial support from the National Institute for Health Research via the Oxford Biomedical Research Centre. SAC has financial support from Autism Speaks/Autistica. We acknowledge the very valuable and longstanding collaboration we have had with the staff of the Oxford Project to Investigate Memory and Ageing (OPTIMA)

\section{Author details}

'Department of Clinical Neurosciences, University of Oxford, Oxford OX3 9DU, UK. ${ }^{2}$ Department of Neuropathology, Oxford Radcliffe NHS Trust, Oxford OX3 9DU, UK.

Published: 1 March 2012

\section{References}

1. Drachman DA: Aging of the brain, entropy and Alzheimer disease. Neurology 2006, 67:1340-1352.

2. Esiri MM: Ageing and the brain. J Pathol 2007, 211:181-187.

3. Savva GM, Wharton SB, Ince PG, Forster G, Matthews FE, Brayne C: Age, neuropathology and dementia. New Engl J Med 2009, 360:2302-2309.

4. Dowling NM, Farias ST, Reed BR, Sonnen JA, Strauss ME, Schnieder JA, Bennett DA, Mungas D: Neuropathological associates of multiple cognitive functions in two community-based cohorts of older adults. J Int Neuropsychol Soc 2011, 17:602-614.

5. Stern Y: Cognitive reserve. Neuropsychologia 2009, 47:2015-2028.

6. Stern $Y$ : What is cognitive reserve? Theory and research application of the reserve concept. J Int Neuropsychol Soc 2002, 8:448-460.

7. Reed BR, Mungas D, Farias ST, Harvey D, Beckett L, Widaman K, deCarli C: Measuring cognitive reserve based on the decomposition of episodic memory variance. Brain 2010, 133:2196-2209.

8. Chance S with: Van Veluw SJ, Sawyer EK, Clover L, Cousijn H, De Jager C, Esiri MM, Chance SA: Prefrontal cortex cytoarchitecture in normal aging and Alzheimer's disease: a relationship with IQ. Brain Struct Funct 2012 DOl:10.1007/s00429-012-0381-x

9. Chance SA, Clover L, Cousijn H, Currah L, Pettingill R, Esiri MM: Microanatomical correlates of cognitive ability and decline: normal ageing, $\mathrm{MCl}$ and Alzheimer's disease. Cerebral Cortex 2011, 21:1870-1878.
10. Terry RD, Masliah E, Salmon DP, Butters N, DeTeresa R, Hill R, Hansen LA, Katzman R: Physical basis of cognitive alterations in Alzheimer disease: synapse loss is the major correlate of cognitive impairment. Ann Neurol 1991, 30:572-580.

11. Sherwood CC, Gordon AD, Allen JS, Phillips KA, Erwin JM, Hof PR, Hopkins WD: Aging of the cerebral cortex differs between humans and chimpanzees. Proc Natl Acad Sci U S A 2011, 108:13029-13034.

12. Brans RB, Kahn RS, Schnack HG, Van Baal GC, Posthuma D, Van Haren NE, Lepage C, Lerch JP, Collins DL, Evans AC, Boomsma DI, Hulshoff Pol HE: Brain plasticity and intellectual ability are influenced by shared genes. J Neurosci 2010, 30:5519-5524.

13. McGurn B, Starr JM, Topfer JA, Pattie A, Whiteman MC, Lemmon HA, Whalley LJ, Deary IJ: Pronunciation of irregular words is preserved in dementia, validating premorbid IQ estimation. Neurology 2004, 62:1184-1186.

14. Mesulam MM: Neuroplasticity failure in Alzheimer's disease: bridging the gap between plaques and tangles. Neuron 1999, 24:521-529.

15. Benes FM, Turtle M, Khan Y, Farol P: Myelination of a key relay zone in the hippocampal formation occurs in the human brain during childhood, adolescence, and adulthood. Arch Gen Psychiatry 1994, 51:477-484.

16. Ehninger D, Kempermann G: Neurogenesis in the adult hippocampus. Cell Tissue Res 2008, 331:243-250.

17. Giedd JN, Blumenthal J, Jeffries NO, Castellanos FX, Liu H, Zijdenbos A, Paus T, Evans AC, Rapoport JL: Brain development during childhood and adolescence: a longitudinal MRI study. Nat Neurosci 1999, 2:861-863.

18. Arendt T: Synaptic plasticity and cell cycle activation in neurons are alternative effector pathways: the Jekyll and Hyde concept of Alzheimer's disease or the yin and yang of neuroplasticity. Progr Neurobio/ 2003, 71:83-248.

19. Esiri MM, Chance SA: Vulnerability to Alzheimer's pathology in neocortex: the roles of plasticity and columnar organization. J Alz Dis 2006, 9:79-89.

20. Grafman J, Litvan I: Evidence for four forms of neuroplasticity. In Neuronal Plasticity: Building a Bridge from the Laboratory to the Clinic. Edited by Grafman J, Christen Y. Springer-Verlag; 1999:131-139.

21. Sowell ER, Peterson BS, Thompson PM, Welcome SE, Henkenius AL, Toga AW: Mapping cortical change across the human life span. Nat Neurosci 2003, 6:309-315.

22. Rosenzweig MR: Effects of differential experience on the brain and behaviour. Dev Neuropsychol 2002, 24:523-540.

23. Gopnik A: How babies think. Sci Am 2010, July:76-81.

24. Chance SA, Casanova MF, Switala AE, Crow TJ, Esiri MM: Minicolumn thinning in temporal lobe association cortex but not primary auditory cortex in normal human ageing. Acta Neuropathologica 2006, 111:459-464.

25. Elston GN, Tweedale R, Rosa MG: Cellular heterogeneity in cerebral cortex: a study of the morphology of pyramidal neurones in visual areas of the marmoset monkey. J Comp Neurol 1999, 415:33-51.

26. Buldyrev SV, Cruz L, Gomez-Isla T, Gomez-Tortosa E, Havlin S, Le R, Stanley HE, Urbanc B, Hyman BT: Description of microcolumnar ensembles in association cortex and their disruption in Alzheimer and Lewy body dementias. Proc Natl Acad Sci U S A 2000, 97:5039-5043.

27. de la Monte SM: Quantitation of cerebral atrophy in pre-clinical and end stage Alzheimer's disease. Ann Neurol 1989, 25:450-459.

28. O'Sullivan M, Jones DK, Summers PE, Morris RG, Williams SCR, Markus HS Evidence for cortical 'disconnection' as a mechanism of age-related cognitive decline. Neurology 2001, 57:632-638.

29. Rose SE, Chen F, Chalk JB, Zelaya FO, Strugnell WE, Benson M, Semple J, Doddrell DM: Loss of connectivity in Alzheimer's disease: an evaluation of white matter tract integrity with colour coded MR diffusion tensor imaging. J Neurol Neurosurg Psychiatry 2000, 69:528-530.

30. Bartzokis G, Lu PH, Geschwind D, Tingus K, Huang D, Medez MF, Edwards N, Mintz J: Apolipoprotein $\mathrm{E}$ affects both myelin breakdown and cognition: implications for age-related trajectories of decline into dementia. Biol Psychiat 2007, 62:1380-1387.

31. Ringman JM, O'Neill J, Geschwind D, Medina L, Apostolova LG, Rodgiguez Y, Schaffer B, Varpetian A, Tseng B, Ortiz F, Fitten J, Cummings JL, Bartzokis G: Diffusion tensor imaging in preclinical and presymptomatic carriers of familial Alzheimer's disease mutations. Brain 2007, 130:1767-1776.

32. Andrews-Hanna JR, Snyder AZ, Vincent JL, Lustig C, Head D, Raichle ME, Buckner RL: Disruption of large-scale brain systems in advanced aging. Neuron 2007, 56:924-935.

33. Rombouts SA, Barkhof F, Goekoop R, Stam CJ, Scheltens P: Altered resting state networks in mild cognitive impairment and mild Alzheimer's 
disease: an fMRI study. Hum Brain Mapp 2005, 26:231-239.

34. Bartzokis $\mathrm{G}$ : Alzheimer's disease as homeostatic responses to age-related myelin breakdown. Neurobiol Aging 2011, 32:1341-1371.

35. Bennett DA, de Jeger PL, Leurgans SE, Schnieder JA: Neuropathologic intermediate phenotypes enhance association to Alzheimer susceptibility alleles. Neurology 2009, 72:1495-1503.

36. Herrup K: Re-imagining Alzheimer's disease - an age-based hypothesis. J Neurosci 2010, 30:16755-16762.

37. Barnes $D E$, Yaffe $K$ : The projected effect of risk factor reduction on Alzheimer's disease prevalence. Lancet Neurol 2011, 10:819-828.

38. Daviglus ML, Plassman BL, Pirzada A, Bell CC, Bowen, PE, Burke JR, Connolly ES, Dunbar-Jacob JM, Granieri EC, McGarry K, Patel D, Trevisan M, Williams JW: Risk factors and preventive interventions for Alzheimer's disease. Arch Neurol 2011, 68:1185-1190

39. Fyffe DC, Mukherjee S, Barnes LL, Manly JJ, Bennett DA, Crane PK: Explaining differences in episodic memory performance among older African Americans and whites: the roles of factors related to cognitive reserve and test bias. J Int Neuropsychol Soc 2011, 17:625038.

40. Hertzog C, Kramer A, Wilson R, Lindenberger U: Enrichment effects on adult cognitive development. Psychol Sci Public Interest 2009, 9:1-65.

41. Clare L, Woods RT, Moniz Cook ED, Orrell M, Spector A: Cognitive rehabilitation and cognitive training for early-stage Alzheimer's disease and vascular dementia (Cochrane Review). Cochrane Database Syst Rev 2003, 4:CD003260.

42. Uchida S, Kawashima R: Reading and solving arithmetic problems improves cognitive functions of normal aged people: a randomized controlled study. Age (Dordr) 2008, 30:21-29.

43. Rozzini L, Costardi D, Vicini Chilovi B, Franzoni S, Trabucchi M, Padovani A: Efficacy of cognitive rehabilitation in patients with mild cognitive impairment treated with cholinesterase inhibitors. Int $J$ Geriatr Psychiatry 2007, 22:356-360.

44. Smith AD, Smith SM, de Jager CA, Whitbread P, Johnston C, Agacinski G, Oulhaj A, Bradley KM, Jacoby R, Refsum H: Homocyteine-lowering by $B$ vitamins slows the rate of accelerated atrophy in mild cognitive impairment: a randomized controlled trial. PlOS ONE 2010, 5:e12244.

45. Barcelo Coblijn G, Hogyes E, Kitajka K, Puskas LG, Zvara A, Hackler L Jr, Nyakas C, Penke Z, Farkas T: Modification by docosahexaenoic acid of age induced alterations in gene expression and molecular composition of rat brain phospholipids. Proc Natl Acad Sci U S A 2003, 100:11321-11326.

46. Lukiw WJ, Cui JG, Marcheselli VL, Bodker M, Botkjaer A, Gotlinger K, Serhan CN, Bazan NG: A role for docosahexaenoic acid derived neuroprotectin D1 in neural cell survival and Alzheimer disease. J Clin Invest 2005, 115:2774-2783

47. Calon F, Lim GP, Yang F, Morihara T, Teter B, Ubeda O, Rostaing P, Triller A, Salem N Jr, Ashe K, Frautschy SA, Cole GM: Docosahexaenoic acid protects from dendritic pathology in an Alzheimer's disease mouse model. Neuron 2004, 43:596-599.

48. Hogervorst E, Williams J, Budge M, Barnetson M, Combrinck, Smith AD: Serum total testosterone is lower in men with Alzheimer's disease. Neuroendocrinol Lett 2001, 22:163-168.

49. Craig MC, Murphy GGM: Estrogen and Alzheimer's dementia. Ann New York Acad Sci 2010, 1205:245-253.

50. Schenk D, Barbour R, Dunn W, Gordon G, Grajeda H, Guido T, Hu K, Huang J, Johnson-Wood K, Khan K, Kholodenko D, Lee M, Liao Z, Lieberburg I, Motter R, Mutter L, Soriano F, Shopp G, Vasquez N, Vandevert C, Walker S, Wogulis M, YednockT, Games D, Seubert P: Immunization with amyloid-beta attenuates Alzheimer disease-like pathology in the PDAPP mouse. Nature 1999, 400:173-177.

51. McGeer PL, Schulzer M, McGeer EG: Arthritis and anti-inflammatory agents as possible protßective factors for Alzheimer's disease: a review of 17 epidemiologic studies. Neurology 1996, 47:425-432.

52. Johnson VE, Stewart W, Smith DH: Traumatic brain injury and amyloid beta pathology: a link to Alzheimer's disease? Nat Rev Neurosci 2011, 11:1-10.

53. Itzahki RF, Wozniak MA: Alzheimer's and infection: do infectious agents contribute to progression of Alzheimer's disease? Alzheimers Dement 2010, 6:83-84.
54. Barres BA: The mystery and magic of glia: a perspective on their roles in health and disease. Neuron 60:430-440.

55. Spence RD, Hamby ME, Umeda E, Itoh N, Du S, Wisdom AJ, Cao Y, Bondar G, Lam J, Ao Y, Sandoval F, Suriany S, Sofroniew MV, Voskuhl RR:

Neuroprotection mediated through estrogen receptor alpha in astrocytes. Proc Natl Acad SciU S A 2011, 108:8867-8872.

56. Abeti R, Abramov AY, Duchen MR: Beta-amyloid activates PARP causing astrocytic metabolic failure and neuronal death. Brain 2011, 134:1658-1672.

57. Kim SU, de Vellis J: Microglia in health and disease. J Neurosci Res 2005, 81:302-318.

58. Schwartz M, Butovsky O, Bruck W, Hanisch UK: Microglial phenotype: is the commitment reversible? Trends Neurosci 2006, 29:68-74.

59. Iadecola C: The overlap between neurodegenerative and vascular factors in the pathogenesis of dementia. Acta Neuropathol 2010, 120:287-296.

60. van Praag H, Shubert T, Zhao C, Gage FH: Exercise enhances learning and hippocampal neurogenesis in aged mice. J Neurosci 2005, 25:8680-8685.

61. Fabel K, Wolf SA, Ehninger D, Babu H, Galicia PL, Kempermann G: Additive effects of physical exercise and environmental enrichment on adult hippocampal neurogenesis in mice. Front Neurosci 2009, 3:50.

62. Kempermann G, Fabel K, Ehninger D, Babu H, Leal-Galicia P, Garthe A, Wolf SA: Why and how physical activity promotes experience-induced brain plasticity. Frontiers Neurosci 2011, 4:189.

63. Hebb DO: The effects of early experience on problem-solving at maturity. Am Psychol 1947, 2:306-307.

64. Itou Y, Nochi R, Kuribayashi H, Saito Y, Hisatsune T: Cholinergic activation of hippocampal neural stem cells in aged dentate gyrus. Hippocampus 2011, 21:446-459.

65. Krech D, Rosenzweig MR, Bennett EL: Effects of environmental complexity and training on brain chemistry. J Comp Physiol Psychol 1960, 53:509-519.

66. Nithianantharajah J, Hannan AJ: The neurobiology of brain and cognitive reserve: Mental and physical activity as modulators of brain disorders. Progr Neurobiol 2009, 89:369-382.

67. Gould E, Reeves AJ, Graziano MS, Gross CG: Neurogenesis in the neocortex of adult primates. Science 1999, 286:548-552.

68. Rakic P: Young neurons for old brains. Nat Neurosci 1998, 1:645-647.

69. Chouliaras L, Sierksma AS, Kenis G, Prickaerts J, Lemmens MA, Brasnjevic I, van Donkelaar EL, Martinez-Martinez P, Losen M, De Baets MH, Kholod N, van Leeuwen F, Hof PR, van Os J, Steinbusch HW, van den Hove DL, Rutten BP: Gene- environment interaction research and transgenic models of Alzheimer's disease. Int J Alz Dis 2010, 2010:pii: 859101.

70. Wang J, Fivecoat H, Ho L, Pan Y, Ling E, Pasinetti GM: The role of Sirt 1: at the crossroads between promotion of longevity and protection against Alzheimer's disease neuropathology. Biochim Biophys Acta 2010 1804:1690-1694.

71. Spilman P, Podlutskaya N, Hart MJ, Debnath J, Gorostiza O, Bredesen D, Richardson A, Strong R, Galvan V: Inhibition of mTOR by rapamycin abolishes cognitive deficits and reduces amyloid beta levels in a mouse model of Alzheimer's disease. Plos ONE 2010, 5:e9979.

72. AlzGene [http://www.alzgene.org/]

73. Farrer LA, Cupples LA, Haines JL, Hyman B, Kukull WA, Mayeux R, Myers RH pericak-Vance MA, Risch N, van Duijn CM: Effects of age, sex and ethnicity on the association between apolipoprotein $\mathrm{E}$ genotype and Alzheimer disease. A meta-analysis. ApoE and Alzheimer disease Meta Analysis Consortium. JAMA 1997, 278:1349-1356

doi:10.1186/alzrt105

Cite this article as: Esiri MM, Chance SA: Cognitive reserve, cortical plasticity and resistance to Alzheimer's disease. Alzheimer's Research \& Therapy 2012, $4: 7$ 